\title{
The promotion of older adults' sense of coherence through Person-centered THERAPY: A RANDOMIZED CONTROLLED PILOT STUDY
}

\author{
Sofia von Humboldt* and ISABel LeaL** \\ "MS. Researcher in Research Unit in Psychology and Health, R\&D, ISPA - Instituto Universitário, \\ Lisbon, Portugal. E-Mail: sofia.humboldt@gmail.com \\ Research Unit in Psychology and Health, R\&D, ISPA - Instituto Universitário. \\ Rua Jardim do Tabaco, 34, 1149-041 Lisboa, Portugal. \\ "PhD. Research Unit Director in Research Unit in Psychology and Health, \\ R\&D, ISPA - Instituto Universitário, Lisbon, Portugal. \\ Authors kindly acknowledge the Portuguese Foundation for Science and Technology (FCT), for the grant: \\ SFRH/BD/44544/2008 which supported this research.
}

\section{RESUMEN}

El objetivo del estudio que se informa fue explorar si una intervención individual de terapia centrada en la persona (TCP) en personas adultas mayores puede promover su sentido de coherencia, en comparación con un grupo control (lista de espera). Se plantea que los participantes asignados al azar a TCP informarían mejoras en SDC de pre y post-intervención en comparación con el grupo control.

Un grupo de 87 participantes de 65 a 86 años $(M=72.4 ; D E=5.15)$ fue evaluado con la Escala de Sentido de Coherencia (ESDC) y el cuestionario sociodemográfico en tres momentos diferentes: al inicio del estudio $\left(t_{1}\right)$, post-tratamiento $\left(t_{2}\right)$ y a los 12 meses de seguimiento $\left(t_{3}\right)$.

Los resultados indicaron que los participantes en TCP evidenciaron un aumento significativo en cuanto a su SDC (16.7\%), mientras que en el grupo control se encontró una disminución significativa (-2.7\%), entre el inicio del estudio y el momento de seguimiento. El tamaño del efecto en el grupo TCP fue alto $\left(\eta^{2} p=.776\right)$. En concreto, tanto en la post-intervención como en el momento del seguimiento, los participantes que se sometieron a TCP tenían un SDC significativamente mayor $(M=3.84, D E=.219)$.
Se encontraron diferencias significativas entre el grupo de intervención y el grupo control en la post-intervención y en el seguimiento.

Se concluye que los cambios en SDC fueron positivos y mantenidos, por lo tanto, los resultados sugieren que la TCP es favorable a la mejora de SDC. Por otra parte, ya que la SDC se asocia con el bienestar relacionado con la salud de las poblaciones de mayor edad, hay que enfatizar el desarrollo de SDC en la vejez.

Palabras clave: Intervención breve; Grupo control; Adultos mayores; Terapia centrada en la persona; Sentido de la coherencia.

\section{ABSTRACT}

Sense of Coherence (SOC) derived from the salutogenic approach and seems to be a health promoting resource, which strengthens resilience and develops a positive subjective state of health. Older adults' SOC is often challenged by specific issues in later adulthood such as grieving for losses, illness, feelings of worthless and solitude, retirement, disability and death, which require distinctive consideration. To our best knowledge, there are no previous studies that indicated the 
relation between a person-centered therapy (PCT) and older adults' SOC. Therefore, this study aims to explore if a brief eight-session individual PCT intervention on older adults can promote their SOC, as compared with a control group (waiting list). Specifically, this is a randomized controlled pilot study designed to explore the promotion of SOC through an individual-based PCT intervention. We posited that participants randomized to PCT would report improvements in SOC from the pre- to the post-intervention moments when compared to those on the waiting list.

The Orientation to Life Questionnaire (OtLQ) and demographics were assessed at the baseline $\left(t_{1}\right)$, post-treatment $\left(t_{2}\right)$ and at the 12-month follow-up $\left(t_{3}\right)$, in a group of 87 participants between 65 - 86 years $(M=72.4 ; S D=5.15)$, from community and health centers in the Great Lisbon area, in Portugal. Participants were mostly women $(59.8 \%)$, married $(65.5 \%)$ and professionally inactive (63.2\%). The Cronbach's Alpha coefficients for SOCS were $.878, .989$, and .988 , in the three moments, respectively.

Inclusion criteria determined their eligibility to participate in the study. No participant with a compromised cognitive function integrated the sample. All potential participants were given a brief description of the study and gave their informed consent. After the baseline assessment, participants were randomly assigned to one of the two groups. The eight-session intervention was conducted in an adequate setting and with a weekly frequency. Comparisons between the three assessments $\left(t_{1}, t_{2}\right.$ and $\left.t_{3}\right)$ for the two groups were done using Repeated Measures ANOVA. Post-hoc Fisher's Least Significant Difference (LSD) test for mean differences was used to compare the three assessments for the SOC, in each group (PCT and waiting list).

After the intervention, a significant increase of $17.3 \%(M=3.86, S D=.218)$ was observed in the participants who did the PCT. The SOC evidenced at follow-up $\left(t_{3}\right)(M=3.84, S D=.219)$ by these participants was significantly higher $(16.7 \%)$ in comparison to the baseline score $(M=3.29$, $S D=.245$ ). Conversely, participants in the control group experienced a minor decrease between baseline $(M=3.28, S D=.236)$ and follow-up $(M=3.19, S D=.244)(-2.7 \%)$. The effect size in the PCT group was high $\left(\eta^{2} p=.776\right)$. Significant differences between the intervention group and the control group were found at the post-intervention and follow-up. Findings also showed that participants in PCT experienced an increment in the three dimensions of SOC. The highest increase was observed in the Comprehensibility dimension (71.2\%). Manageability and Meaningfulness subscales showed an increase of $32.9 \%$ and $12.1 \%$, respectively.

Changes in SOC were positive and maintained, thus, findings suggest that PCT is favorable to enhancing SOC. In particular, for the participants who did PCT, the significant increase of their SOC was mainly due to the high increase of the comprehensibility of events. This study contributed to filling a gap in gerontological literature and this intervention has the potential to offer a reasonably low-cost self-regulatory approach to the SOC. In this context, PCT is also a personal resource to promote SOC, in late adulthood. Moreover, since SOC is associated with health-related well-being among older populations, SOC development in old age should be stressed.

Key words: Brief intervention; Control group; Older adults; Person-centered therapy; Sense of coherence.

\section{INTRODUCTION}

Europe is the continent with the oldest population in the world. By 2025, about onethird of Europe's population will be aged 60 or over, with greatest increase being among its oldest citizens (World Health Organization, 2002). Moreover, the health and well-being of older people was recognized as one of the most pressing and universal social issues of our time (Antonucci, Okorodudu, \& Akiyama, 2002). In this way, psychological research is needed on the development of physical and mental health in late life, and on interventions that promote psychological and physical health of older adults (Fernández-Ballesteros, 2007).

The psychological literature abounds in studies of sense of coherence (SOC) (Amirkhan 
\& Greaves, 2003; Becker, Glascoff, \& Felts, 2010; Dilani, 2008; Eriksson \& Lindstrom, 2005, 2006; Lundberg \& Nyström, 1994; Suominen, Helenius, Blomberg, Uutela, \& Koskenvuo, 2001; Surtees, Wainwright, Luben, Khaw, \& Day, 2003; Volanen, Lahelma, Silventoinen, \& Suominen, 2004; Volanen et al., 2010). Sense of coherence refers to a global orientation expressing a person's pervasive, enduring though dynamic, feeling of confidence. Individuals with a strong SOC, perceive stimuli from their environment as making sense, structured and predictable (comprehensibility), as being under their own control or of others' (Manageability), and as being worthy of investment and engagement (Meaningfulness) (Antonovsky, 1979, 1987, 1993). The SOC derived from the salutogenic approach, that is, the search for the causes of health rather than the bases of disease (Palacios-Espinosa, \& Restrepo-Espinosa, 2008). Thus, SOC seems to be a health promoting resource, which strengthens resilience and develops a positive subjective state of health (Eriksson \& Lindstrom, 2006). In previous literature, SOC has been found to be positively associated with quality of life (Motzer \& Stewart, 1996; Shiu, 2003), well-being (Söderberg, Lundman, \& Nordberg, 1997; Petrie \& Brook, 1992), subjective state of health (Palacios-Espinosa, \& Restrepo-Espinosa, 2008, Suominen et al., 2001), health behaviors (Henje Blom, Serlachius, Larsson, Theorell, \& Ingvar, 2010; Suominen et al., 1999; Vuori, 1994), self-esteem (Petrie, \& Brook, 1992), emotional coping and optimism (Eriksson \& Lindstrom, 2005) and negatively with morbidity and mortality (Poppius, Tenkanen, Kalimo, \& Heinsalmi, 1999; Poppius, Tenkanen, Hakama, Kalimo, \& Pitkänen, 2003; Surtees, Wainwright, Luben, Khaw, \& Day, 2003; Virués-Ortega, Martínez-Martí, Luis, \& Lozano, 2007). Furthermore, there has been a growing body of research about SOC in older populations (Lundman et al., 2010; Wiesmann, Niehörster, \& Hannich, 2009). Indeed, previous research suggested a relationship between a high level of SOC and a positive selfperception about older adults' health status (Zamora, Sánchez, \& Olvera, 2010), and decreased mortality (Virués-Ortega et al., 2007). Moreover, the protective effect of SOC towards illness in late adulthood was also identified (Vásquez, 2007).

Person-centered approach pulls against the whole idea of dividing into body and mind and further into elements of mind such as personality and even self. Instead it focuses in human growth, development and full functionality (Schmid \& O' Hara, 2013; Segrera, 1997). Moreover, person-centered therapy (PCT) places a high value on the individual's psychological independence and integrity (Sanders, 2007). Furthermore, it focuses on understanding older clients from within their own frames of reference and individual ways of experiencing and on finding ways to promote growth and development with, rather than for, them (Pörtner, 2008).

Whilst therapeutic skills related to ethical and legal issues, end-of-life decision-making, abuse and self-neglect, cultural diversity and self-reflection, as well as a method for the understanding of the social and psychological dynamics of the aging process are important in a model for PCT with older adults, critical for the PCT, are the therapeutic attitudinal conditions brought to the encounter with the older adult (Pörtner, 2008; Washburn \& von Humboldt, 2013).

Common themes when working with older adults, such as grieving for losses, illness, feelings of worthless and solitude, retirement, disability and death, influence SOC and require distinctive consideration when deciding on the manner in which the older adults are approached (Bugelli, 2008; Hamarat, Thompson, Steele, Matheny, \& Simons, 2002). Praxis traditions of PCT are particularly suited to older adults, whose personhood is sometimes unacknowledged by others but whose losses are balanced by gains and growth (Bohart \& Tallman, 1999; Cooper \& McLeod, 2011; Freire, 2013).

In this context, PCT provides the opportunity for a deeply negative or despairing experience to be expressed, fully felt and received empathically as a reality of experience (Asay \& Lambert, 1999; Barrett-Lennard, 2007, Cain, 2013; Freire, 2013), through relational 
depth (Knox \& Cooper, 2010; Mearns \& Schmid, 2006), congruence (Levitt, 2005; Rogers, 1959, 1980) and non-directiveness (Bozarth, 2002; Brodley, 1997; Witty, 2004).

Researchers regard transformations in clients' emotional experiencing as core to the change process in psychotherapy (Kottler, Sexton, \& Whiston, 1994; Watson \& Lilova, 2009) and a positive outcome in therapy (Patterson, 1984; Rogers, 1951, 1959). Specifically in late adulthood, changes may affect older adults' worldview and thus their SOC (Antonovsky, 1987; Wiesmann et al., 2009).

Considering that PCT focuses on the potential for positive change towards full functionality (Levitt, 2005; Rogers, 1980), the older individual with a strong SOC has a greater ability to mobilize and exploit potential resources (Antonovsky, 1979, 1987).

To date, little attention has been paid to studies exploring PCT in the literature of older adults and its relation with SOC. Thus, this study aims to make a relevant contribution to the existing literature by focusing on the SOC of older adults who participated in an individual-based PCT intervention. This is a randomized controlled pilot study designed to explore the promotion of SOC through an individual-based PCT intervention. In detail, the aims of this study were the following: (a) to assess and compare older adults' SOC before and after a PCT intervention, (b) to analyse SOC dimensions scores (i.e., Comprehensibility, Manageability and Meaningfulness) for the PCT group, and (c) to explore significant differences between the PCT and the control group after the intervention and at follow-up. We hypothesized that those assigned to PCT would report increases in SOC compared to those in the control condition.

\section{Methods}

\section{PARTICIPANTS}

A community-dwelling sample of 87 eligible participants, with ages between 65 and 89 years $(M=72.4 ; S D=5.15)$, were recruited from community and health centers in the
Great Lisbon area, in Portugal. Participants were mostly women (59.8\%) and professionally inactive $(63.2 \%)$. There were no changes in the status of any of the demographic variables across time. Table 1 shows the sociodemographic and health-related characteristics of the participants.

When analyzing the crossing of the different socio-demographic variables, most of the participants who were married or in a relationship were inactive whilst single older adults, were mostly professionally active. Additionally, a higher number of older men than women showed a higher annual income, as presented in Table 2 .

\section{MeAsuRes}

The socio-demographic and health characteristics were evaluated in a first moment through a self-reported questionnaire. SOC was assessed, using the Orientation to Life Questionnaire (OtLQ - Antonovsky, 1993), a 29-item semantic differential scale, rated from 1 (never) to 7 (always), with a good internal consistency $(\alpha=.82)$ and composed by three subscales (Comprehensibility sample item: "When you talk to people, do you have the feeling that they don't understand you?"; Manageability - sample item: "Has it happened that people whom you counted on, disappointed you?" and Meaningfulness - sample item: "Do you have the feeling that you don't really care about what goes on around you?"). The OtLQ presented overall good psychometric properties (in terms of construct and criterion related validities and reliability), in previous studies (Antonosvky, 1993; Eriksson, \& Lindstrom, 2005), namely with older populations (Virués-Ortega, et al., 2007).

In the current study, the Cronbach's Alpha coefficients at baseline $\left(t_{1}\right)$, post-intervention $\left(t_{2}\right)$ and follow-up $\left(t_{3}\right)$ was $.878, .989$, and .988 , respectively. All reliability coefficients were .80 or higher, thus we considered them to have good levels of reliability. The main variables that were studied in the present research were the SOC, Comprehensibility, 
Manageability and Meaningfulness scores. Socio-demographic variables were solely used for the sample characterization.

\section{Procedure}

Potential participants were first given a brief description of the study, and then they underwent a phone and face-to-face screening to determine eligibility. Participants were eligible to participate if they: (1) were 65 years of age or older, and (2) scored within the normal range on the Mini Mental Status Exam - MMSE - (> 26) (Folstein, M., Folstein, S., $\&$ Mc Hugh, 1975). None of the participants had any history of psychiatric or neurological illness, or history of drug or alcohol abuse, which might compromise cognitive function.

Of 89 individuals initially meeting study inclusion criteria, two were excluded for assorted miscellaneous reasons (e.g., scheduling and transportation problems, inability to commit to 8 weekly sessions).

We collected data from the subjects at three different moments, thus the sequence of the intervention was the following: (1) The first set of data was collected one week before the beginning of PCT sessions (or control condition) at baseline. At baseline $\left(t_{1}\right)$, participants completed the informed consent, MMSE, the OtLQ and demographics. (2) After the baseline assessment, participants were randomly assigned to one of the two groups and one of the groups had eight PCT sessions. (3) One week after the intervention period $\left(t_{2}\right)$, a second assessment was conducted. (4) Followup $\left(t_{3}\right)$ was conducted 12 months after the end of the intervention.

The sessions were conducted by a clinical psychologist with PCT experience with older populations and who had no previous relationship with the participants. The therapist assumed a neutral position in order to avoid investigation bias. Neutrality was kept by ensuring that the findings were a function solely of the participants and conditions of the research, with no researchers' input.

The PCT intervention was structured, after a literature review and based on previous interventions. The intervention consisted of individual 45-minute sessions, conducted in an adequate setting and with a weekly frequency. Each PCT session was performed under the adequate PCT therapeutic conditions and setting for the understanding of the social and psychological dynamics of the older adults and the aging process. The therapist took a nondirective role and assured three therapeutic attitudinal conditions: congruence; unconditional positive regard; and empathy (Pörtner, 2008; Sanders, 2007), core of this therapy. Some of the participants asked to be appraised of the results at the end the study.

A total of 87 participants who were randomized to PCT or control group, there were 44 participants who integrated and completed the 8-week PCT and 43 who were on a waiting list for an equivalent amount of time. We used a 1:1 ratio method to ensure that there was a sufficient sample size for conducting analyses in the experimental condition. No participants were lost to follow-up (PCT, $n=44$; control group, $n=43$ ) resulting in a final sample of 87 , that was used for statistical analyses. Figure 1 demonstrates participant flow through the study.

The Portuguese Foundation for Science and Technology (FCT) and ISPA - Instituto Universitário, approved the study. Informed consent was received from all participants and the study protocol was approved by the Research Unit in Psychology and Health's coordination.

\section{StATISTICAL ANALYSES}

Data was first analyzed to check for outliers and distribution forms. No missing value imputation was made. To explore if at baseline the two groups were homogeneous, a $t$ Student test was used to compare both conditions, on the SOC variable.

Comparisons between the three assessments $\left(t_{1}, t_{2}\right.$ and $\left.t_{3}\right)$ for the two groups were done using Repeated Measures ANOVA. Post-hoc Fisher's Least Significant Difference (LSD) test for mean differences was used to compare the three assessments for the SOC, 
in each group (PCT and waiting list). Data were analyzed using SPSS for Windows (version 19.0).

\section{RESULTS}

In general, our results showed that the intervention gave these older participants the opportunity for sharing their personal experience and narratives in a psychologically safe therapeutic setting, during which the relational process and attitudes, inherent to PCT, facilitated the promotion of their SOC.

Regarding our first objective, that is, to assess and to compare older adults' SOC before and after a PCT intervention, findings showed that participants in PCT evidenced a significant increase of their SOC (16.7\%), whilst those in waiting list indicated a significant decrease $(-2.7 \%)$, between baseline and follow-up, as seen in Table 3. Concerning SOC dimensions' scores (i.e., Comprehensibility, Manageability and Meaningfulness) for the PCT group, results showed that participants in PCT experienced an increment in the three dimensions of SOC. The highest increment was verified in the Comprehensibility dimension (71.2\%), followed by Manageability (32.9\%) and Meaningfulness (12.1\%) dimensions. Complete descriptive information for SOC and its subscales is provided in Table 3.

Our third objective was to explore significant differences between the PCT and the control group after the intervention and at follow-up.

To accomplish this objective we firstly verified if the participants who did PCT differed from the ones who were attributed to the waiting list, in the three assessments, regarding the SOC. As seen in Table 4, results from the $t$-Student indicated that the two groups did not significantly differ at baseline assessment, concerning SOC. Conversely, they significantly differ at $t_{2}$ and $t_{3}$.

Secondly, to explore if the variables changed during the three assessments, within SOC, the PCT and waiting list groups were analyzed separately, after the verification of sphericity for all variables/groups with the Mauchly test. Specifically, both at the postintervention, and at follow-up, participants who underwent PCT had a significantly higher SOC $(M=3.84, S D=.219)$. Significant differences between the intervention group and the control group were found at the postintervention and follow-up. The effect size in the PCT group was high $\left(\eta^{2} p=.776\right)$. Results from the repeated measures ANOVA for the PCT group and control group in the three assessments $\left(t_{1}, t_{2}\right.$ and $\left.t_{3}\right)$ are presented in Table 5.

\section{Discussion}

The central aim of this randomized controlled pilot study was to explore the promotion of SOC through an individual-based PCT intervention. In doing so, this study contributes to the literature in two ways. Firstly, our results highlighted the pertinence of older adults' SOC. Secondly, the results suggested that individual PCT with older adults may enhance their SOC. The findings, as well as the strengths and limitations of this study, are discussed in more detail subsequently.

Our first objective was to assess and to compare older adults' SOC before and after a PCT intervention. Findings showed that after the intervention, a significant increase of $17.3 \%(M=3.86, S D=.218)$ was observed in the participants who did PCT. Moreover, the SOC evidenced at follow-up $\left(t_{3}\right)(M=3.84$, $S D=.219)$ by these participants was significantly higher $(16.7 \%)$ in comparison to the baseline score $(M=3.29, S D=.245)$. Inversely, participants in control group experienced a minor decrease between baseline $(M=3.28$, $S D=.236)$ and follow-up $(M=3.19$, $S D=.244$ ) (that is, a mean $2.7 \%$ significant decrease of their score). Moreover, between $t_{1}$ and $t_{2}$ the control group had a mean $1.2 \%$ reduction of their score $(M=3.24, S D=.233)$. Effective PCT is a process of developmental healing, through relational depth (BarrettLennard, 2007; Knox \& Cooper, 2010; Mearns \& Schmid, 2006). The interrelated attitudes (congruence, unconditional positive 
regard and empathy) on the part of the therapist are central to the success of PCT (Freire, 2013; Sanders, 2007), and for the occurrence of psychological changes (Kottler, Sexton, \& Whiston, 1994) and a positive outcome in therapy (Patterson, 1984; Rogers, 1951, 1959). However, it must be noted that PCT, although effective for most clients as traditionally practiced, has its limitations, as do all therapeutic approaches (Rogers, 1959). Alternatively, researchers suggest that PCT can be optimized in effectiveness by integrating methods from other models, such as focusingoriented therapy, expressive therapy or emotion-focused therapy (Cain, 2013).

Our results support the fact that individual PCT may promote older adults SOC. However, the therapy format (group versus individual) has been subject of debate. For instance, significant differences were not previously found in terms of the intervention's efficacy when comparing group with individual interventions (Schmid \& O' Hara, 2013).

Our second aim was to analyse SOC dimensions scores (i.e., Comprehensibility, Manageability and Meaningfulness) for the PCT group. Results showed that participants in PCT experienced an increment in the three dimensions of SOC. In detail, the highest increase was observed in the Comprehensibility dimension (71.2\%). Manageability and Meaningfulness subscales showed an increase of $32.9 \%$ and $12.1 \%$, respectively. Although we expected that PCT would increase the Meaningfulness dimension, the results indicated that the increment in SOC was mostly due to the increase of the Comprehensibility dimension. This dimension regards the extent to which events are perceived as making logical sense, i.e., being ordered, consistent, and structured (Antonovsky, 1993; Eriksson \& Lindstrom, 2006). Hence, in our study, the participants who did PCT, showed a significant increase of their comprehensibility of events. Considering that SOC is a health promoting psychological resource, which strengthens one's capacity to deal with environmental strain (Volanen et al., 2010), PCT privileges the client's perspective over the therapist's and it moves away from a diagnostic of problem-centered understanding of the client, emphasizing where the client wants to "go" (Bohart \& Tallman, 1999; Cooper \& McLeod, 2011).

In addition to this, Rogers' necessary and sufficient conditions provided, by a genuine therapist, are pivotal in terms of facilitating therapeutic personality change (Asay \& Lambert, 1999). PCT empowers the client, through non-directiveness (Bozarth, 2002; Brodley, 1997; Witty, 2004), congruence, comprehensibility and psychological adjustment towards decision-making and full functionality (Cooper \& McLeod, 2011; Levitt, 2005; Rogers, 1980). Moreover, our findings indicated that the effect size in the PCT group was strong (.776). These results are in line with previous studies that suggested that the relational process between the therapist and the client during PCT can produce effects (Witty, 2005). In particular, approximately $30 \%$ of the variance in the PCT outcome can be attributed to common factors, which include the relationship, with $40 \%$ relating to client factors such as social learning and health, $15 \%$ relating to specific techniques, and $15 \%$ reflecting expectancy or hope for the success of therapy (Asay \& Lambert, 1999). Alternatively, research stressed that older adults may also benefit from other models such as cognitive-behavioral therapy (CBT). However literature on the effectiveness of CBT in older adults is still limited because less research has been conducted with this population generally (Cox \& D' Oyley, 2011).

Additionally, we found no previous studies that indicated the effect of PCT on older adults' SOC. Hence, it is possible that the relational process and attitudes, inherent to PCT, have mediated the promotion of SOC among our participants.

Finally, our third objective was to explore significant differences between the PCT and the control group after the intervention and at follow-up. In our study, SOC was significantly different in both groups, after the intervention and at follow-up. It has been reiterated the need to address the challenge of maintaining health and well-being in old age (FernándezBallesteros, 2007). Rogers (1959, 1980) expressed the idea of the mechanisms of 
change, under conditions of freedom, safety and understanding, which basically involve the client taking on the above cited therapeutic attitudinal conditions with the result of making better choices. Our findings showed that participants involved in PCT presented a higher SOC after the intervention, in comparison with those in the control group. Previous studies found SOC to be associated with well-being indicators (Söderberg et al., 1997; Petrie \& Brook, 1992) and with health (Henje et al., 2010). In fact SOC, seems to be a potential reason or mediating process for psychosocial variation in health (Suominen et al., 1999). Considering that social and personality factors are among the key determinants of health and well-being (Volanen et al., 2004), SOC seems to be a health promoting resource, which strengthens resilience and develops a positive subjective state of health (Amirkhan \& Greaves, 2003; Eriksson \& Lindstrom 2006).

Our study offers a valuable contribution to the literature. Yet, the results need to be interpreted within the context of the following limitations. Although a diverse sample of participants was recruited, this pilot study is limited by a small sample size and reliance on self-report measures. Moreover, the propensity for this study to be generalized is limited by the use of a convenience sampling method. In fact, the study was confined to participants who were recruited from community and health centers. Alternatively, generalized results to the older Portuguese population would represent the psychological and cultural diversity of this population.

Furthermore, although significant differences were found between groups, their clinical relevance is yet to be determined. Therefore, these findings need to be interpreted for practical use in order to avoid overrating differences, although the results showed statistical significance. Additionally, we hypothesized that an intervention with a clinical sample may enhance comparative results including community and clinical samples.

It is also not known whether the therapeutic attitudes that are central to other therapeutic models (e.g., focusing-oriented therapy) would allow for similar outcomes in different therapy models. Additionally, cognitive factors and the establishment of clear objectives, components that are approached in CBT, were not part of our intervention. Future comparative interventions with older adults may clearly benefit of including outcomes from interventions with several therapeutic models.

It was not entirely evident from just comparing PCT and control groups that the therapeutic attitudinal conditions provided within PCT, solely influenced or promoted SOC among older adults. Indeed, no in-depth interviews were performed. Qualitative interviews may had provided the means for a deep understanding of what actually constitutes older adults' experiences of SOC. In addition, our study is limited by the three assessment moments of SOC. Thus, longitudinal and sequential designs are further needed to explain the stability of the found results.

This study was also limited for the lack of a comparative intervention format. Alternatively, comparative group interventions may be particularly stimulating to explore in future research. In addition, the measurement of SOC itself has limitations. Although the SOC questionnaire was originally developed by Antonovsky himself, it may still need further development in order to capture the key ideas in the SOC theory. A full-scale trial should next test whether PCT produces parallel changes in other measures of well-being (e.g., quality of life and subjective well-being).

It is unknown whether the results found persisted beyond the follow-up period used in this study. Thus, it might have been helpful to have maintenance sessions after the conclusion of the weekly intervention sessions. Because some participants were unable to commit to the 8-week structured program due to transportation and scheduling issues, it may also be optimal to develop and test other modes of delivering this and other forms of psychosocial interventions for this population. This intervention has the potential to offer a reasonably low-cost self-regulatory approach to the SOC.

In spite of the limitations we believe that the findings of this study contribute to a better understanding of the promotion of SOC 
through PCT. Firstly, the data come from a randomized controlled pilot study. Secondly, besides the data, the study suggested the potential benefits of a PCT intervention on their SOC. Thirdly, this study contributed to filling a gap in gerontological literature. Indeed, we found no previous studies that have focused on whether PCT can promote older adults' SOC or not.

In brief, the present study focused on exploring the promotion of an individual based PCT intervention in older adults and our findings suggest that PCT may increase SOC.

Therefore, this study also provides a basis for more research, specifically, designing and implementing effective intervention programs, in which SOC and other well-being indicators can be included, in order to contribute to a better understanding of older adults' specific needs. PCT interventions seem to be, thus, pertinent, as a means of promoting SOC within a salutogenic context among older populations. 
von Humboldt and Leal

TABLE 1

DISTRIBUTION OF THE STUDY'S PARTICIPANTS ACCORDING TO SOCIO-DEMOGRAPHIC AND HEALTH-RELATED CHARACTERISTICS $(N=87)$

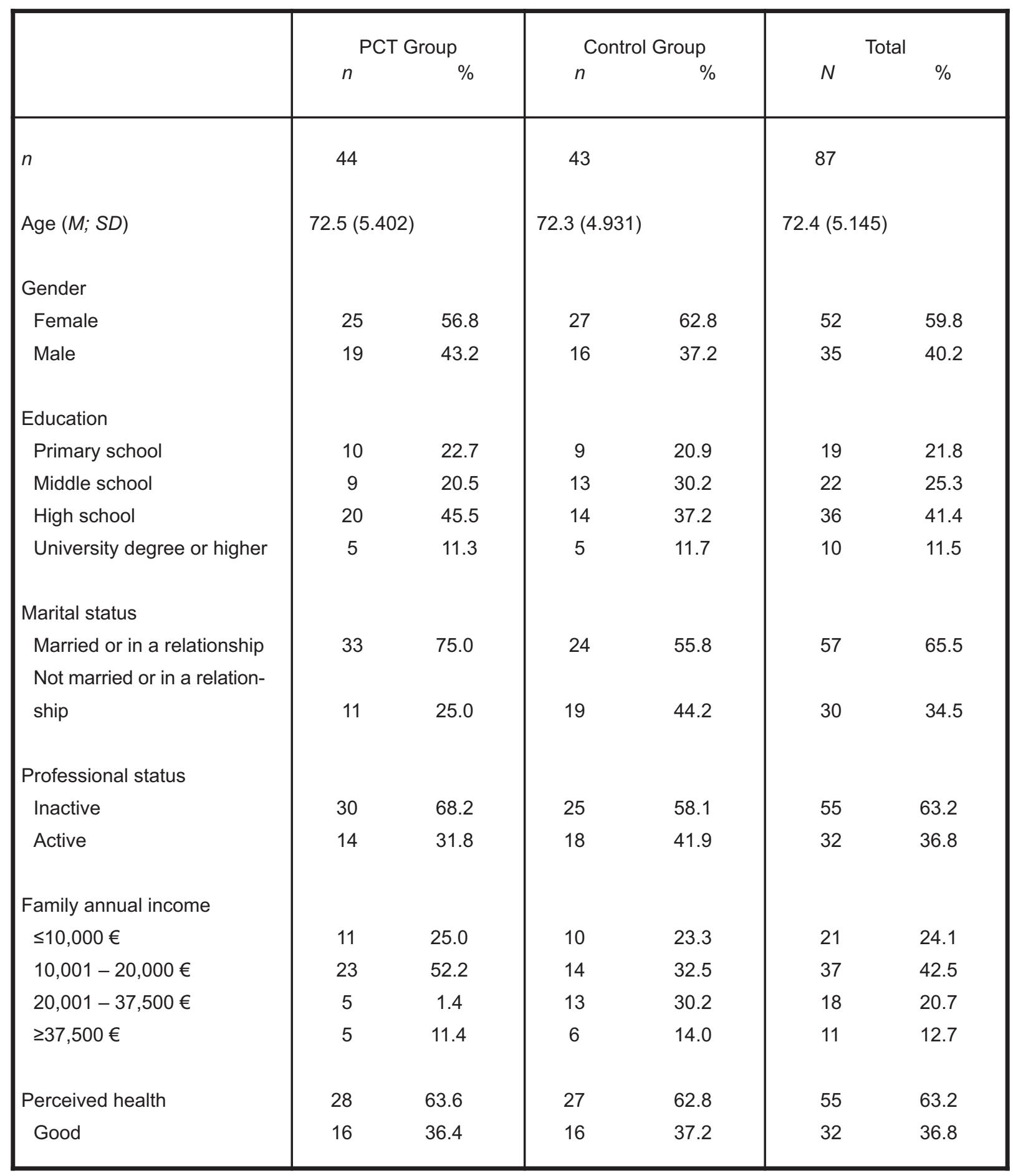


TABLE 2

DISTRIBUTION OF SOCIO-DEMOGRAPHIC CHARACTERISTICS BY GENDER, MARITAL STATUS, PROFESSIONAL STATUS AND FAMILY ANNUAL INCOME

\begin{tabular}{|c|c|c|c|c|c|c|c|c|}
\hline & \multicolumn{2}{|c|}{ Marital status } & \multicolumn{2}{|c|}{ Professional status } & \multicolumn{4}{|c|}{ Family annual income } \\
\hline & $\begin{array}{l}\text { Married } \\
\text { or in a } \\
\text { relationship }\end{array}$ & $\begin{array}{l}\text { Not married } \\
\text { or in a } \\
\text { relationship }\end{array}$ & Inactive & Active & $\leq 10,000 €$ & $10,001-20,000 €$ & $20,001-37,500 €$ & $\geq 37,500 €$ \\
\hline \multicolumn{9}{|l|}{ Gender } \\
\hline Female & 35 & 17 & 34 & 18 & 16 & 22 & 9 & 5 \\
\hline Male & 22 & 13 & 21 & 14 & 5 & 15 & 9 & 6 \\
\hline \multicolumn{9}{|l|}{ Marital status } \\
\hline Married or in a relationship & - & - & 43 & 14 & 13 & 24 & 12 & 8 \\
\hline Not married or in a relationship & - & - & 12 & 18 & 8 & 13 & 6 & 3 \\
\hline \multicolumn{9}{|l|}{ Professional status } \\
\hline Inactive & - & - & - & - & 12 & 22 & 13 & 8 \\
\hline Active & - & - & - & - & 9 & 15 & 5 & 3 \\
\hline \multicolumn{9}{|l|}{ Family annual income } \\
\hline$\leq 10,000 €$ & - & - & - & - & - & - & - & - \\
\hline $10,001-20,000 €$ & - & - & - & - & - & - & - & - \\
\hline $20,001-37,500 €$ & - & - & - & - & - & - & - & - \\
\hline$\geq 37,500 €$ & - & - & - & - & - & - & - & - \\
\hline
\end{tabular}


TABLE 3

MEANS AND STANDARD DEVIATIONS ON THE SENSE OF COHERENCE SCORE

\begin{tabular}{|l|c|c|c|}
\hline & $\begin{array}{c}\text { Baseline } \\
\left(t_{1}\right) \\
(M ; S D)\end{array}$ & $\begin{array}{c}\text { Post-intervention } \\
\left(t_{2}\right) \\
(M ; S D)\end{array}$ & $\begin{array}{c}\text { Follow-up } \\
\left(t_{3}\right) \\
(M ; S D)\end{array}$ \\
\hline PCT Group $\left(g_{1}\right)$ & & & \\
SOC & $3.29(.245)$ & $3.86(.218)$ & $3.84(.219)$ \\
Comprehensibility & $2.26(.712)$ & $3.90(.412)$ & $3.87(.416)$ \\
Manageability & $3.01(.486)$ & $4.02(.399)$ & $4.00(.390)$ \\
Meaningfulness & $3.21(.353)$ & $3.61(.286)$ & $3.60(.285)$ \\
Control group $\left(g_{2}\right)$ & & & \\
SOC & $3.28(.236)$ & $3.24(.233)$ & $3.19(.244)$ \\
Comprehensibility & $3.61(.322)$ & $3.57(.318)$ & $3.53(.321)$ \\
Manageability & $2.99(.481)$ & $2.96(.489)$ & $2.94(.500)$ \\
Meaningfulness & $3.19(.331)$ & $3.14(.340)$ & $3.05(.354)$ \\
& & & \\
\hline
\end{tabular}

TABLE 4

COMPARISON OF PARTICIPANTS PLACED IN INTERVENTION (PCT) WITH PARTICIPANTS IN WAITING LIST (WL) AT BASELINE ASSESSMENT $\left(t_{1}\right)$, POST-INTERVENTION $\left(t_{2}\right)$ AND FOLLOW-UP $\left(t_{3}\right)$

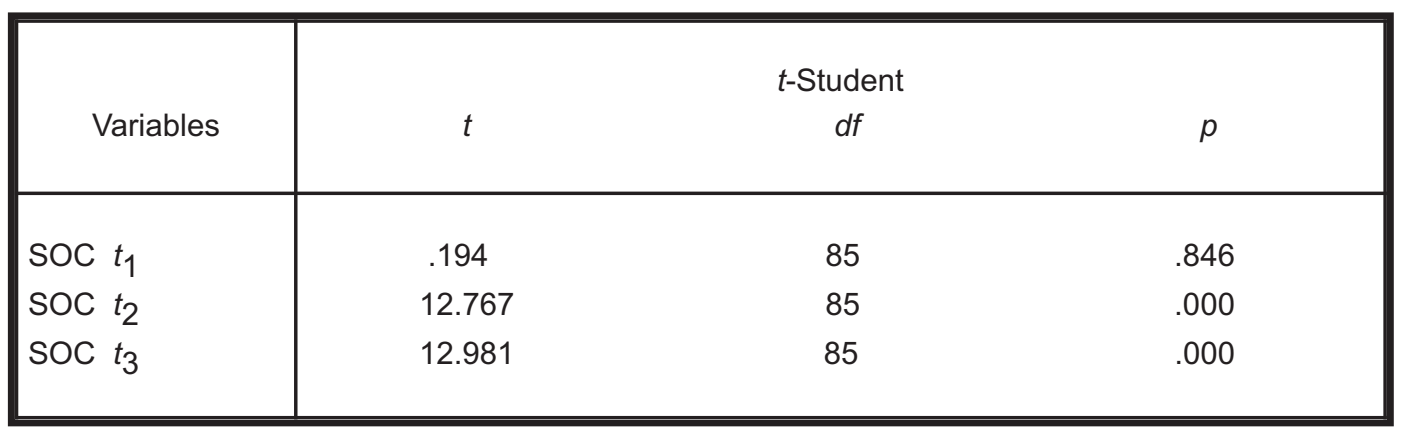


TABLE 5

PCT GROUP AND CONTROL GROUP: COMPARISON BETWEEN BASELINE $\left(t_{1}\right)$, POST-INTERVENTION $\left(t_{2}\right)$ AND FOLLOW-UP $\left(t_{3}\right)$ ASSESSMENTS FOR SOC $(N=87)$

\begin{tabular}{|l|ccc|cc|c|c|}
\hline Variables & $\begin{array}{c}t_{1} \\
M(S D)\end{array}$ & $\begin{array}{c}t_{2} \\
M(S D)\end{array}$ & $\begin{array}{c}t_{3} \\
M(S D)\end{array}$ & $\mathrm{I}$ & $\mathrm{J}$ & $\begin{array}{c}\text { Mean Difference } \\
\text { I-J(SE)p }\end{array}$ & $\eta^{2} p$ \\
\hline $\begin{array}{l}\text { SOC } \\
\text { for PCT } \\
\text { Group }\end{array}$ & $3.29(.245)$ & $3.86(.218)$ & $3.84(.219)$ & $t_{1}$ & $t_{2}$ & $-.567(.046) .000$ & .776 \\
& & & & $t_{3}$ & $-.546(.045) .000$ & \\
& & & $t_{2}$ & $t_{3}$ & $.020(.006) .001$ & \\
\hline $\begin{array}{l}\text { SOC for } \\
\text { Gontrol }\end{array}$ & $3.28(.236)$ & $3.24(.233)$ & $3.19(.244)$ & $t_{1}$ & $t_{2}$ & $.042(.009) .000$ & .454 \\
& & & & $t_{3}$ & $.089(.013) .000$ & \\
\hline
\end{tabular}

FIGURE 1

PARTICIPANT FLOW THROUGH THE STUDY

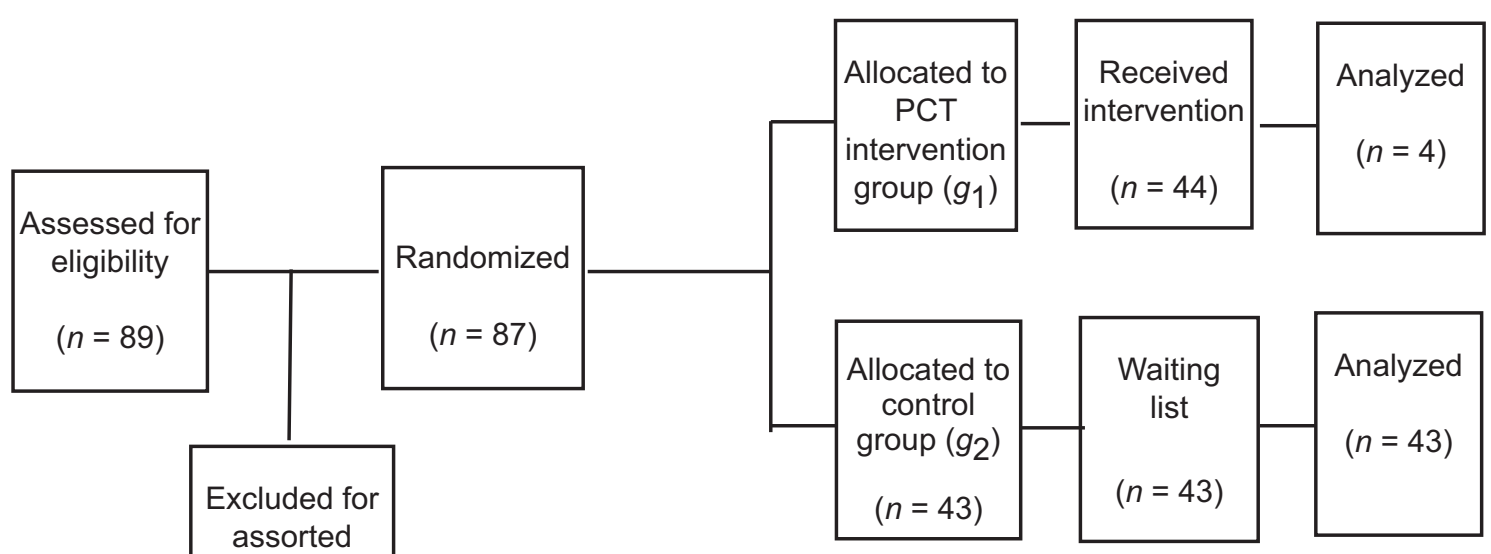
reasons $(n=2)$ 


\section{REFERENCES}

Amirkhan, J.H., \& Greaves, H. (2003). Sense of coherence and stress: The mechanics of a healthy disposition. Psychology and Health, 18(1), 31-62. http://dx.doi.org/10.1080/0887 044021000044233

Antonovsky, A. (1979). Health, stress and coping. San Francisco: Jossey-Bass.

Antonovsky, A. (1987). Unraveling the mystery of health - How people manage stress and stay well. San Francisco: Jossey-Bass.

Antonovsky, A. (1993). The structure and properties of the Sense of Coherence Scale. Social Science \& Medicine, 36, 725-33.

Antonucci, T.C., Okorodudu, C., \& Akiyama. (2002). Well-being among older adults on different continents. Journal of Social Issues, 58, 767-783. http://dx.doi.org/10.1111/1540-45 60.00280

Asay, T., \& Lambert, M. (1999). The empirical case for the common factors. In M. Hubble, B. Duncan, \& S. Miller (Eds.), The heart and soul of change (pp. 23-55). Washington, DC: American Psychological Association. http:// dx.doi.org/10.1037/11132-001

Barrett-Lennard, G.T. (2007). The relational foundations of person-centered practice. In M. Cooper, M. O'Hara, P. F. Schmid, \& G. Wyatt (Eds.), The handbook of person-centered psychotherapy and counseling (pp. 127-139). New York, NY: Palgrave Macmillan.

Becker, C.M., Glascoff, M.A., \& Felts, W.M. (2010). Salutogenesis 30 years later: Where do we go from here? International Electronic Journal of Health Education, 13, 25-32.

Bohart, A.C., \& Tallman, K. (1999). How clients make therapy work: The process of active self-healing. Washington DC: American Psychological Association.

Bozarth, J.D. (2002). Nondirectivity in the person-centered approach: Critique of Kahn's critique. Journal of Humanistic Psychology,
42, 78-83. http://dx.doi.org/10.1177/002216 7802422007

Brodley, B.T. (1997). The nondirective attitude in client-centered therapy. The Person-Centered Journal, 4, 18-30.

Bugelli, T. (2008). Motivational interviewing and the older population in psychiatry. The Psychiatrist, 32, 23-25. http://dx.doi.org/10.11 92/pb.bp.106.010405

Cain, D.J. (2013). Older adults. In M. Cooper, M. O'Hara, P.F. Schmid, \& A.C. Bohart (Eds.), The handbook of person-centered psychotherapy and counseling (2nd ed.) (pp. 248260). New York, NY: Palgrave Macmillan.

Cooper, M., \& McLeod, J. (2011). Person-centered and experiential psychotherapies, 10 (3), 210-223. http://dx.doi.org/10.1080/1477 9757.2011.599517

Cox, D., \& D' Oyley, H. (2011). Cognitive-behavioral therapy with older adults. British Columbia Medical Journal, 53(7), 348-352.

Dilani, A.P.D. (2008). Psychosocially supportive design: A salutogenic approach to the design of the physical environment. Design and Health Scientific Review, 1(2), 47-55.

Eriksson, M., \& Lindstrom, B. (2005). Validity of Antonovsky's sense of coherence scale: A systematic review. Journal of Epidemiology and Community Health, 59, 460-466. http://d x.doi.org/10.1136/jech.2003.018085

Eriksson, M., \& Lindstrom, B. (2006). Antonovsky's sense of coherence scale and the relation with health: a systematic review. Journal of Epidemiology and Community Health, 60, 376-381. http://dx.doi.org/10.1136/jech.2005.0 41616

Fernández-Ballesteros, R. (2007). GeroPsychology: European perspectives for an aging world. Gottingen: Hogrefe and Huber.

Folstein, M., Folstein, S., \& McHugh, P. (1975). Mini-Mental State: A practical method for grading the cognitive state of patients for clinician. Journal of Psychiatric Research, 12, 189-198. 
Freire, E.S. (2013). Empathy. In M. Cooper, M. O'Hara, P.F. Schmid, \& A.C. Bohart (Eds.), The handbook of person-centered psychotherapy and counseling (2nd ed.) (pp. 165-179). New York, NY: Palgrave Macmillan.

Hamarat, E., Thompson, D., Steele, D., Matheny, K., \& Simons, C. (2002). Age differences in coping resources and satisfaction with life among middle-aged, young-old and oldest-old adults. The Journal of Genetic Psychology, 163, 360-367. http://dx.doi.org/10.1080/002 21320209598689

Henje Blom, E.C., Serlachius, E., Larsson, J.O., Theorell, T., \& Ingvar, M. (2010). Low Sense of Coherence (SOC) is a mirror of general anxiety and persistent depressive symptoms in adolescent girls - a cross-sectional study of a clinical and a non-clinical cohort. Health Quality Life Outcomes, 8, 58. http://dx.doi. org/10.1186/1477-7525-8-58

Knox, R., \& Cooper, M. (2010). Relationship qualities that are associated with moments of relational depth: The client's perspective. Person-Centered and Experiential Psychotherapies, 9(3), 236-256. http://dx.doi.org/ 10.1080/14779757.2010.9689069

Kottler, J.A., Sexton, T.L., \& Whiston, S.C. (1994). The heart of healing: Relationships in therapy. San Francisco: John Wiley.

Levitt, B. (2005). Embracing non-directivity: Reassessing person-centered theory and practice in the 21st Century. Ross-on-Wye: PCCS Books.

Lundberg, O., \& Nyström, P.M. (1994). Sense of coherence, social structure and health. Evidence from population survey in Sweden. European Journal of Public Health, 4, 252257. http://dx.doi.org/10.1093/eurpub/4.4.252

Lundman, B., Forsberg, K.A., Jonsén, E., Gustafson, Y., Olofsson, K., Strandberg, G., \& Lövheim, H. (2010). Sense of coherence (SOC) related to health and mortality among the very old: The Umeå 85+ study. Archives of Gerontology and Geriatrics, 51(3), 329-332. http://dx.doi.org/10.1016/j.archger.2010.01.0 13

Mearns, D., \& Schmid, P.F. (2006). Being-with and being-counter: Relational depth: The challenge of fully meeting the client. PersonCentered and Experiential Psychotherapies, 5(4), 255-265. http://dx.doi.org/10.1080/147 79757.2006.9688417

Motzer, S., \& Stewart B. (1996). Sense of coherence as a predictor of quality of life in persons with coronary heart disease surviving cardiac arrest. Journal Research in Nursing \& Health, 19(4), 287-298. http://dx.doi.org/10.1002/(SI CI)1098-240X(199608)19:4<287::AIDNUR3 $>3.3 . \mathrm{CO} ; 2-\mathrm{W}$

Palacios-Espinosa, X., \& Restrepo-Espinosa, M. H. (2008). Aspectos conceptuales e históricos del sentido de coherencia propuesto por Antonovsky: ¿Una alternativa para abordar el tema de la salud mental? [Conceptual and historical aspects of the sense of coherence proposed by Antonovsky: an alternative to approach the mental health issue?]. Informes Psicológicos, 10(11), 275-300.

Patterson, C.H. (1984). Empathy, warmth and genuineness in psychotherapy. A review of reviews. Psychotherapy, 21, 431-438. http://dx. doi.org/10.1037/h0085985

Petrie, K., \& Brook, R. (1992). Sense of coherence, self-esteem, depression and hopelessness as correlates of reattempting suicide. British Journal Clinical Psychology, 31, 293300. http://dx.doi.org/10.1111/j.2044-8260.1 992.tb00996.x

Poppius, E., Tenkanen, L., Kalimo, R., \& Heinsalmi, R. (1999). The sense of coherence, occupation and the risk of coronary heart disease in the Helsinki Heart Study. Social Science and Medicine, 49(1), 109-120. http:// dx.doi.org/10.1016/S0277-9536(99)00105-7

Poppius, E., Tenkanen, L., Hakama, M., Kalimo, R., \& Pitkänen, T. (2003). The sense of coherence, occupation and all-cause mortality in the Helsinki Heart Study. European Journal 
of Epidemiology, 18, 389-393. http://dx.doi. org/10.1023/A:1024213427147

Pörtner, M. (2008). Being old is different: Person-centred care for old people. Ross-onWye, UK: PCCS Book.

Rogers, C. (1951). Client-centered Therapy: Its current practice, implications and theory. London: Constable.

Rogers, C.R. (1959). A theory of therapy, personality and interpersonal relationships, as developed in the client-centered framework. In S. Koch (Ed.), Psychology: A study of science (pp. 184-256). New York, NY: McGraw Hill.

Rogers, C.R. (1980). Client-centered psychotherapy. In H.I. Kaplan \& B.J. Sadock, (Eds.), Comprehensive textbook of Psychiatry. Baltimore: Williams and Wilkins. http://dx. doi.org/10.1038/scientificamerican1152-66

Sanders, P. (2007). Introduction to the theory of person-centred therapy. In M. Cooper, M. O'Hara, P. F. Schmid, \& G. Wyatt (Eds.), The handbook of person-centered psychotherapy and counseling (pp. 9-18). New York, NY: Palgrave Macmillan.

Schmid, P.F., \& O' Hara, M. (2013). Working with groups. In M. Cooper, M. O'Hara, P.F. Schmid, \& A.C. Bohart (Eds.), The handbook of person-centered psychotherapy and counseling (2nd ed.) (pp. 223-236). New York, NY: Palgrave Macmillan.

Segrera, A.S. (1997). Carl Ransom Rogers: Su vida y obra [Carl ransom Rogers. His life and work]. In O. Solís (Eds.), La otra voz: Psicoterapia y filosofia (pp. 257-266). Córdoba, Veracruz, México: Arróniz.

Shiu A. (2003). Sense of coherence amongst Hong Kong Chinese adults with insulin-treated type 2 diabetes. International Journal Nursing Studies, 41, 387-396. http://dx.doi.org/1 0.1016/j.ijnurstu.2003.10.010

Söderberg, S., Lundman, B., \& Nordberg, A. (1997). Living with fibromyalgia: Sense of coherence, perception of well-being and stress in daily life. Research in Nursing \& Health,
20, 495-503. http://dx.doi.org/10.1002/(SI CI) 1098-240X(199712)20:6<495::AIDNUR4>3.3.CO;2-D

Suominen, S., Blomberg, H., Helenius, H., \& Koskenvuo, M. (1999). Sense of coherence and health: Does the association depend on resistance resources? A study of 3115 adults in Finland. Psychology and Health, 15, 1-12. http://dx.doi.org/10.1080/0887044990840735 8

Suominen, S., Helenius, H., Blomberg, H., Uutela, A., \& Koskenvuo, M. (2001). Sense of coherence as predictor of subjective state of health. Results of 4 years of follow-up of adults. Journal of Psychosomatic Research, 50, 77-86.

Surtees, P., Wainwright, N., Luben, R., Khaw, K., \& Day, N. (2003). Sense of coherence and mortality in men and women in the EPICNorfolk United Kingdom prospective cohort study. American Journal of Epidemiology, 158(12), 1202-1209. http://dx.doi.org/10.10 93/aje/kwg272

Vásquez, M.D. (2007). Sentido de coherencia, afrontamiento, y sobrecarga en cuidadores familiares de ancianos con enfermedad crónica [Sense of coherence, coping and overload in family caregivers of older adults with chronic disease]. Avances en Psicología Latinoamericana, 25(1), 64-71.

Virués-Ortega, J., Martínez-Martín, P., Luis, J.D. B., \& Lozano, L.M. (2007). Validación transcultural de la Escala de Sentido de Coherencia de Antonovsky (OLQ-13) en ancianos mayores de 70 años [Transcultural validation of the Sense of Coherence Scale (OLQ-13) among 70-year old older adults]. Medicina Clinica, 128(13), 486-492.

Volanen, S.M., Lahelma, E., Silventoinen, K., \& Suominen, S. (2004). Factors contributing to sense of coherence among men and women. European Journal of Public Health, 14(3), 322-330. http//dx.doi.org/10.1093/eurpub/14. 3.322 
Volanen, S.M., Suominen, S., Lahelma, E., Koskenvuo, K., Koskenvuo, M., \& Silventoinen, K. (2010). Sense of coherence and intentions to retire early among Finnish women and men. BMC Public Health, 10, 22. http://dx. doi.org/10.1186/1471-2458-10-22

Vuori, J. (1994). Pre-employment antecedents of health resources, job factors and health risk behaviour in men and women. Work Stress, 8 , 263-277. http://dx.doi.org/10.1080/02678379 408259998

Washburn, A., \& von Humboldt, S. (2013). Older adults. In M. Cooper, M. O'Hara, P.F. Schmid, \& A.C. Bohart (Eds.), The handbook of person-centered psychotherapy and counseling (2nd ed.) (pp. 297-312). New York, NY: Palgrave Macmillan.

Watson, J., \& Lilova, S. (2009). Testing the reliability and validity of the scales for experiencing emotion with a canadian sample. Person-Centered \& Experiential Psychotherapies Journal, 8(3), 189-207. http://dx. doi.org/10.1080/14779757.2009.9688488
Wiesmann, U., Niehörster, G., Hannich, H.J. (2009). Subjective health in old age from a salutogenic perspective. British Journal of Health Psychology, 14, 767-87.

Witty, M. (2004). The difference directiveness makes: The ethics and consequences of guidance in psychotherapy. The Person-Centered Journal, 11, 22-32.

Witty, M. (2005). Non-directiveness and the problem of influence. In B.E. Levitt (Ed.), Embracing non-directivity: Reassessing person-centered theory and practice in the 21st Century (pp. 228-247). Ross-on-Wye, UK: PCCS Books.

World Health Organization. (2002). Active aging. A policy framework. Geneva, Switzerland: World Health Organization.

Zamora, H., Sánchez, E., \& Olvera, Y.L. (2010). Sense of coherence and health in self-perceived healthy aged people. Revista Costarricense de Psicología, 29(43), 17-34. 
$\otimes$ 